\title{
Extraction of Lactic Acid from Whey of Yoghurt by Solvent Extraction Technique
}

\author{
JAMAL STAS*, MARWA YOUSEF \\ Atomic Energy Commission of Syria, Department of Chemistry, POBox 6091, Damascus-Syria
}

\begin{abstract}
The aim of this paper is to investigate the possibility to recover lactic acid (LA) from the whey of yoghurt by easy and effective solvent extraction technique using tri-n-octylamine, tri-n-butyl phosphate, and their mixtures as extractant. All parameters affecting the transfer of lactic acid to the organic phase were investigated including: time of stirring, tri-n-butyl phosphate and tri-n-octylamine concentrations, organic to aqueous phase ratio, temperature, $\mathrm{NaCl}$ concentration as a salting out agent, and number of contacts. The maximum yield of LA extraction can be obtained by using the following operation conditions: $0.8 \mathrm{MTOA}+11 \% \mathrm{TBP}, \mathrm{V}_{\mathrm{org}} / \mathrm{V}_{a q}=4 / 1, t=30^{\circ} \mathrm{C},[\mathrm{NaCl}]=2 \mathrm{M}$. Complete stripping of LA from loaded organic phase can be done in 2 stages using double distilled water at $60^{\circ} \mathrm{C}$ and $V_{\text {aq }} / V_{\text {org }}=20 / 1$.
\end{abstract}

Keywords. extraction, lactic acid, whey, trioctylamine, tributylphosphate

\section{Introduction}

Lactic acid (LA) is one of many organic acids which are widely used in food industry, pharmaceutical products, cosmetics [1], since lactate esters are good solvents for polymers and resins and could replace ketones and other polar solvents used in the polymer industry. And can be used for cleaning circuit boards and machine and engine parts. Unlike conventional solvents, lactate esters ex-hibit low toxicity, and not hazardous air pollutants. Polylactides which are prepared from LA have variety of uses including moldings, fibers, films, and packaging of goods and food products. This incredible acid is obtained by fermentation process using high-grade sugar or sugar-rich resources such as molasses in the presence of homolactic acid organisms (Lactobacillus delbrueckii, ....) to keep the fermentation running, the $p \mathrm{H}$ needs to be kept at 5-6 [2]. So $\mathrm{Ca}(\mathrm{OH})_{2}$ should be added to neutralize the produced LA. Then $\mathrm{H}_{2} \mathrm{SO}_{4}$ was added to the formed calcium lactate to produce LA. And gypsum $\left(\mathrm{CaSO}_{4} \cdot 2 \mathrm{H}_{2} \mathrm{O}\right)$ will be generated. To prevent the formation of huge amounts of gypsum and extract pure LA from fermentation broth, a new technology should be used [2].

Verra Habova et al 2004 [3] developed a chemical process to recover LA from fermentation broth using electrodialysis technique. Firstly, lactate was recuperated from pretreated fermentation broth by ultrafiltration technique and concentrated by desalting electrodialysis, then in second step was electroconversion of lactate to lactic acid by water-splitting electrodialysis.

George Kuchoukov et al [4] investigated the extraction of LA by a mixture of tri-n-octylamine and Aliquat 336 in decanol they deduced that the combination of a tertiary amine and quaternary ammonium salt is more efficient than the individual extractants.

Tatsumi Yamamoto et al [5] thoroughly studied the extraction of LA using a combination of di and tri-n-octylamine dissolved in non polar diluents or the combination of non-polar diluents in the presence of a modifier, they discovered that almost all the portion of LA can be successfully and effectively extracted when di-octylamine overpasses the initial concentration of LA in aqueous phase and that TOA have little capacity for the extraction when it is dissolved in non-polar diluents. They pointed out that adding the modifier (decanol) to a non-polar diluents is also demonstrated to be effective for ameliorating the extraction ability of TOA.

*email: cscientific19@aec.org.sy 
Michiaki Matsumoto et al [6] utilized reactive solvent extraction and an aqueous two phase system to extract 3-hydroxypropionic acid, they mentioned that TOA diluted in 1-octanol gave the highest extractability in the reactive extraction system and there was little effect on the extractability of 3-HP by the addition of salt to the system.

Kanungnit Chawong et al [7] deeply studied the recovery of LA from its aqueous solutions at $30^{\circ} \mathrm{C}$ in a mixed solvent electrolyte system containing water, 1-butanol and ammonium sulfate $\left.\left(\mathrm{NH}_{4}\right)_{2} \mathrm{SO}_{4}\right)$. They stated that in view of extraction, ternary combination containing water, 1-butanol and LA, $\left(\mathrm{NH}_{4}\right)_{2} \mathrm{SO}_{4}$ effectively salted out 1-butanol and LA leading to a reduced quantity of these two components in the aqueous phase.

Mutakul Mungma et al [8] investigated the uptake of LA from alkaline aqueous solutions using ammonium-based ionic liquid (Aliquat 336) and its carbonated form, they pointed out the enhancement of extraction efficiency when carbonate form of Aliquat 336 was used and also, the use of polar-aprotic chemicals like MIBK was significantly more effective in terms of LA extraction than alcohol like 1octanol or 1-heptanol. And the use of solvent combinations containing Aliquot 336 in the carbonated form and the modifier MIBK diluted in n-hexane was a successful attempt to ameliorate the extraction capacity.

In ORNL/TM-2004/192 [9], several ionic liquids have been investigated for the extraction of organic acids from fermentation broth, distributing of lactic, acetic and succinic acids between aqueous solution and nine hydrophobic ionic liquids was examined, the extraction efficiencies were strongly dependent on $p \mathrm{H}$ of the aqueous feed solution. And the distribution coefficient was so good $(\sim \mathrm{D} \simeq 60)$ at low succinic acid concentrations for one of the ionic liquids (trihexyl tetradecyl phosphonium methanesulfonate) at a neutral $p \mathrm{H}$. A modifier like nonanol is advised to be added to the mixture, they suggested that an extraction system based on ionic liquids may be feasible for succinic acid recovery from fermentation broth and two extraction stages are needed to reduce the concentration of succinic acid from $33 \mathrm{~g} / \mathrm{L}$ to $1 \mathrm{~g} / \mathrm{L}$.

Qianzhu Li et al [10] passionately studied the interphase distribution of three organic acids in systems involving five different imidazolium-based ionic liquids and analyzed the findings which clarified that hydrophobicity, concentration of organic acid, alkyl chain of the cation and anion of the ionic liquids and $p \mathrm{H}$ of the extraction system could affect the extraction capacity. Additionally, the back extraction of organic acid from ionic liquids (ILs) into distilled water could be up to $81 \%$.

The recovery of aconitic and lactic acids from dilute aqueous effluents of sugarcane industry by solvent extraction technique has been investigated by Guy Malmary et al [11], reactive extraction of carboxylic acids with tributyl phosphate/dodecane was examined at $25^{\circ} \mathrm{C}$, and for 3 extractant concentrations of $50 \%, 60 \%$ and $70 \%(\mathrm{w} / \mathrm{w})$ in dodecane. They suggested that TBP can be considered as a promising extractant for large-scale application.

Whey is a by-product of the dairy industry, until recently, treated as a sewage, since it generate a substantial biochemical oxygen demand, concerns and regulation have become important issue [12], in this regard, many researchers started to carry out studies on the composition and processing of whey for its use in foods and animal feeds besides studying the nutritive, therapeutic and functional properties of whey, LA is also one of the constituent of the whey, and can be recovered for its economic value and its valuable uses in many industries as described above.

In this paper we will focus on LA extraction by hydrometallurgical method from whey of yoghurt using a mixture of TOA and TBP diluted in kerosene and investigate the effects of all parameters affecting the extraction and des-extraction processes and suggesting the best operating conditions to recover LA.

\section{Materials and methods}

\subsection{Reagent}

All chemicals used in this study were of analytical grade, tri-n-butyl phosphate (TBP) with purity of $99 \%$ was from BDH, tri-n-octylamine (TOA) with purity of $95 \%$ was from FLUKA, 1- octanol with 
purity of $98 \%$ was from PROLABO, kerosene containing less than $0.5 \%$ aromatics was from PEMCO Chemicals Company, $0.1 \mathrm{~N}$ sodium hydroxide ampoules were from Merck, and double distilled water was prepared locally at AECS.

Whey of yoghurt was obtained from the home-made yoghurt by simple filtration, and farther filtration was done to the whey using filter paper (Type, Whatman 41), then the whey was kept in refrigerator.

\subsection{Lactic acid solvent extraction procedure}

The extraction of LA was done by magnetically stirring the desired volume of aqueous (whey of yoghurt) and organic phases (TBP/kerosene, TOA/kerosene, or TBP+TOA/kerosene) in conical flasks situated in thermo-stated water bath, at constant temperature. Then, the organic phases were separated from aqueous phases after $24 \mathrm{~h}$ of settlement.

\subsection{Lactic acid analysis}

Concentration of lactic acid was determined by titrating a known volume of filtered whey of yoghurt with a suitable concentration of sodium hydroxide $(0.1,0.01,0.001 \mathrm{~N})$ using an automatic potentiometric titrator (AT-420N-WIN) from KYOTO ELECTRONICS, Japan.

The distribution ratio $(D)$ and the yield of extraction ( $\mathrm{Y}_{\mathrm{LA}} \%$ ) of $L A$, were calculated as follows:

$$
\begin{gathered}
\mathrm{D}=\frac{\text { Total concentration of LA in the organic phase }(\mathrm{M})}{\text { Total concentration of LA in the aqueous phase }(\mathrm{M})} \\
\mathrm{D}=\frac{[\mathrm{LA}]_{\mathrm{org}}}{[\mathrm{LA}]_{\mathrm{aq}}} \\
\mathrm{Y}_{\mathrm{LA}} \%=\frac{[\mathrm{LA}]_{\mathrm{org}} \cdot \mathrm{V}_{\mathrm{org}}}{[\mathrm{LA}]_{\mathrm{aq}} \cdot \mathrm{V}_{\mathrm{aq}}} \times 100
\end{gathered}
$$

where: $[\mathrm{LA}]_{\mathrm{org}},[\mathrm{LA}]_{\mathrm{aq}}$ are the concentration $(\mathrm{mol} / \mathrm{L})$ of $L A$ in the organic and aqueous phase respectively.

$: \mathrm{V}_{\mathrm{org}}, \mathrm{V}_{\mathrm{aq}}$ are the volume $\left(\mathrm{cm}^{3}\right)$ of organic and aqueous phase respectively.

The concentration of major elements $(\mathrm{Ca}, \mathrm{Mg}, \mathrm{Na}, \mathrm{K}, \mathrm{Zn})$ in the whey of yoghurt was determined by atomic absorption spectrometer and presented in Table 1.

Table 1. Total concentration of major important elements in whey of yoghurt.

\begin{tabular}{|c|c|c|c|c|c|}
\hline Element & $\mathrm{Ca}$ & $\mathrm{Mg}$ & $\mathrm{Na}$ & $\mathrm{K}$ & $\mathrm{Zn}$ \\
\hline $\begin{array}{c}\text { Concentration } \\
(\mu \mathrm{g} / \mathrm{mL})\end{array}$ & $1828 \pm 183$ & $196 \pm 20$ & $3565 \pm 357$ & $2079 \pm 208$ & $3 \pm 0.3$ \\
\hline
\end{tabular}

The high concentration of $\mathrm{Na}$ in the whey is attributed to the addition of $\mathrm{NaCl}$ into the yoghurt during the filtration process of yoghurt to prepare Labaneh, it is noteworthy to mention that Labanet is the most consumed and sold dairy product after yoghurt in the Arabian countries exist in the middle east.

\section{Results and discussions}

\subsection{Extraction of lactic acid by tri-n-butyl phosphate}

2- hydroxyl proionic acid (LA), which is known as lactic acid was extracted from whey of yoghurt by two series of organic extractants, the first series is consisted of $0.1,0.5,1,1.5,2,2.5$, and $3 \mathrm{~mol} / \mathrm{L}$ of TBP diluted in kerosene, while the second series is consisted of $0.1,0.5,1,1.5$, and $2 \mathrm{~mol} / \mathrm{L}$ of TBP 
diluted in kerosene and containing $44 \%(\mathrm{v} / \mathrm{v})$ of 1 - octanol as modifier. The two series of extractants were stirred for 30 min with whey of yoghurt at $\mathrm{V}_{\mathrm{org}} / \mathrm{V}_{\mathrm{aq}}=1$ and maintaining constant temperature of $30^{\circ} \mathrm{C}$ during the extraction process. Then the organic and aqueous phases were separated after $24 \mathrm{~h}$ of settlement at $30^{\circ} \mathrm{C}$, the results of extraction were graphically illustrated in Figure 1 in the form of yield of LA extraction and distribution ratio against TBP concentration in the organic phase.

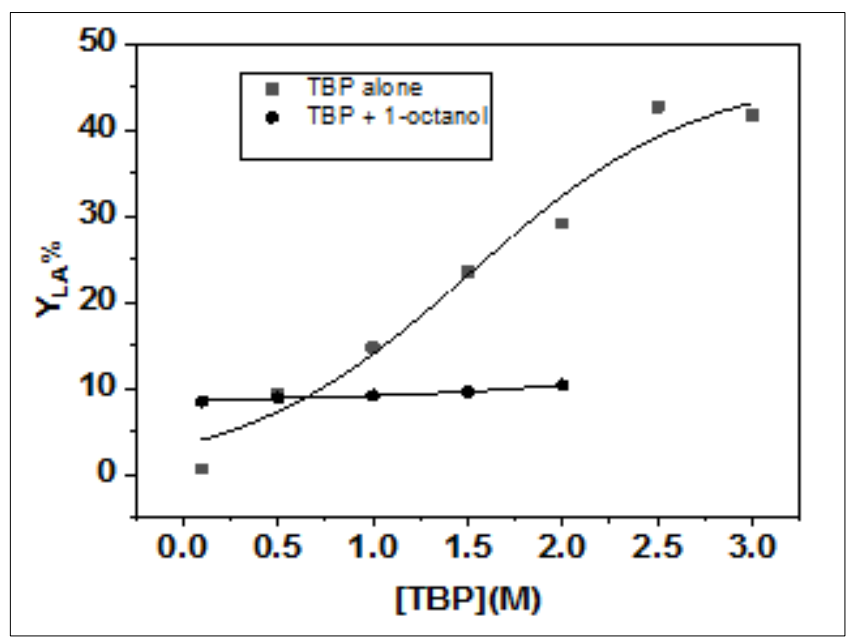

Figure 1. Effect of TBP on distribution ratio and the yield of LA extraction

Using TBP alone to extract LA (Figure 1a) caused the formation of third phase, and LA distributed in the two formed organic phases, the total content of LA in the two organic phases [heavy (in the top) and light (in the middle)] was increased by increasing TBP concentration in the organic phase and the maximum extraction yield $\mathrm{Y}_{\max }{ }^{\mathrm{LA}}=42 \%$ was observed at 2.5 to $3 \mathrm{~mol} / \mathrm{L} \mathrm{TBP} / \mathrm{kerosene}$. Adding 1octanol as a modifier to TBP has good effect in accelerating the separation of organic phase from aqueous phase, but unfortunately the extraction yield of lactic acid was poor and not exceeded $10 \%$ for all TBP concentrations used (Figure 1b) in this experiments, this low yield $\mathrm{Y}_{\mathrm{LA}} \%$ can be explained by the fact that, a hydrogen bound will be formed between the oxygen atom of TBP and hydroxyl group of 1-octanol leading to a competition between LA and 1-octanol to interact and bound with TBP.

\subsection{Extraction of lactic acid by tri-n-octylamine}

\subsubsection{Effect of stirring time on LA extraction}

Lactic acid was extracted from whey of yoghurt by $0.4 \mathrm{M}$ trioctylamine containing $11 \%(\mathrm{v} / \mathrm{v}) \mathrm{TBP}$ at $30^{\circ} \mathrm{C}$ and maintaining constant volume phase ratio of $\left(\mathrm{V}_{\mathrm{org}} / \mathrm{V}_{\mathrm{aq}}=1\right)$ and varying the stirring time from 1 to $240 \mathrm{~min}$. It was found that the extraction reaction reaches the equilibrium state after $1 \mathrm{~h}$ of stirring with nearly $20 \%$ extraction yield. No significant changes of $\mathrm{Y}_{\mathrm{LA}} \%$ was observed in the range of (60240 mins), consequently, all the following experiments related to LA extraction by TOA will be carried out at $1 \mathrm{~h}$ of stirring to insure equilibration.

\subsubsection{Effect of tri-n-octylamine concentration on LA extraction}

To investigate the effect of tri-n-octylamine on LA extraction, an aqueous phase of whey of yoghurt was stirred for $1 \mathrm{~h}$ with a series of TOA solutions having the following concentrations: $0.4,0.6,0.8,1$, 1.2 and $1.5 \mathrm{~mol} / \mathrm{L}$, and containing $11 \%(\mathrm{v} / \mathrm{v}) \mathrm{TBP}$ in kerosene at $\mathrm{V}_{\text {org }} / \mathrm{V}_{\text {aq }}=1$ and $30^{\circ} \mathrm{C}$. The results were presented in Figure $2 a$ and $b$ in the form of $\log D_{\mathrm{LA}}$ and $\mathrm{Y}_{\mathrm{LA}} \%$ against $\log [\mathrm{TOA}]_{\mathrm{i}}$ and $[\mathrm{TOA}]_{\mathrm{i}}$ concentration in the organic phase respectively. The extraction of LA is dependent to TOA concentration (Figure $2 b$ ) and $\mathrm{Y}_{\mathrm{LA}} \%$ increases with rising TOA concentration in the organic phase, the maximum extraction yield $\mathrm{Y}_{\mathrm{LA}}{ }^{\max }=33.3 \%$ was observed for $[\mathrm{TOA}]=1.5 \mathrm{~mol} / \mathrm{L}$ which is not satisfactory because of low extractability of LA. Therefore, other parameters such as $\mathrm{V}_{\text {org }} / \mathrm{V}_{\mathrm{aq}}, \mathrm{TBP} \%$, Temperature, $\mathrm{NaCl}$ 
concentration in feed solution and number of contacts should be tested in combination with TOA concentration to increase the capacity of LA recovery. The plot of $\log \mathrm{D}_{\mathrm{LA}}$ against Log TOA (Figure 2a) gives a straight line with a slop of 0.723 and good correlation coefficient of $r=0.985$ that's mean 1 mol of tri-n-octylamine reacts with one mol of LA.

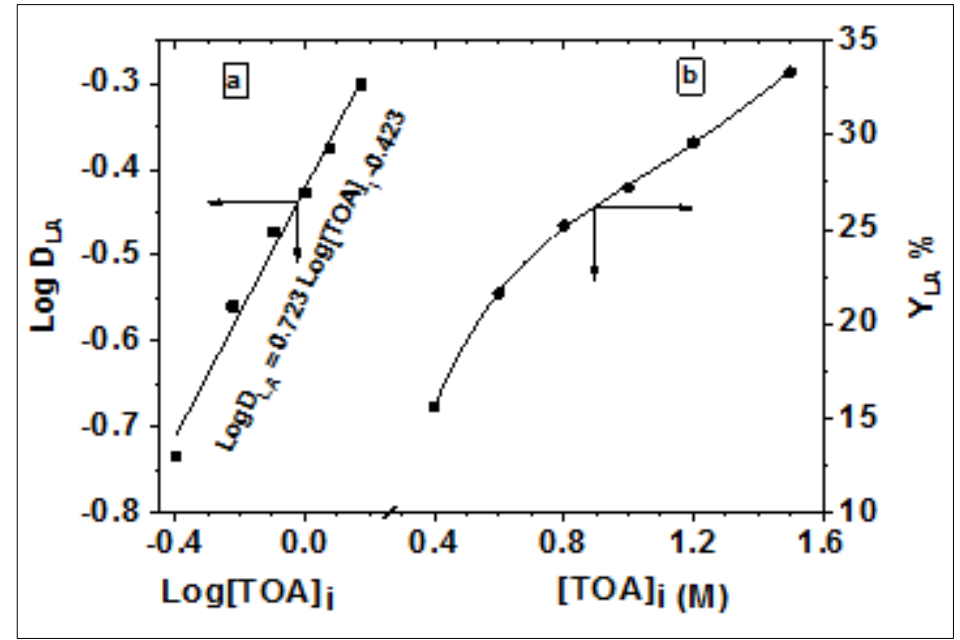

Figure 2a, b. Effect of tri-n-octylamine on $\mathrm{D}_{\mathrm{LA}}$ and $\mathrm{Y}_{\mathrm{LA}} \%$

\subsubsection{Effect of TBP at constant TOA concentration on LA extraction}

From previous experiments, it has been shown that adding TBP to TOA had a good effect especially on phase separation between organic and aqueous phase during the settlement process, and no third phase was observed. TBP alone had the power to extract LA, but a third phase was formed. In this investigation an organic phase of $0.8 \mathrm{M}$ TOA/kerosene containing different percentage of TBP were put into contact with an aqueous phase of whey of yoghurt and stirred for $1 \mathrm{~h}$ at $30^{\circ} \mathrm{C}$ and $\mathrm{V}_{\text {org }} / \mathrm{V}_{\mathrm{aq}}=1$, then the aqueous and organic phase were separated after $24 \mathrm{~h}$ of settlement. The results were presented in Figure $3 \mathrm{a}$ and $\mathrm{b}$ in the form of distribution ratio and yield of LA extraction ( $\mathrm{Y}_{\mathrm{LA}} \%$ ) as a function of tributyl phosphate percentage in the organic phase respectively. From Figure $3 \mathrm{a}$ and $\mathrm{b}$ it is obvious that $\mathrm{D}_{\mathrm{LA}}$ and $\mathrm{Y}_{\mathrm{LA}} \%$ increases with increasing $\mathrm{TBP} \%$ in the organic phase and reaches a maximum of extractability $\mathrm{Y}_{\mathrm{LA}}=65 \%$ at $40 \%$ TBP. So, adding TBP to TOA improved the extraction of LA from whey and prevented the formation of third phase, consequently the synergistic mixture of TOA+TBP is a promising organic phase to extract LA from whey.

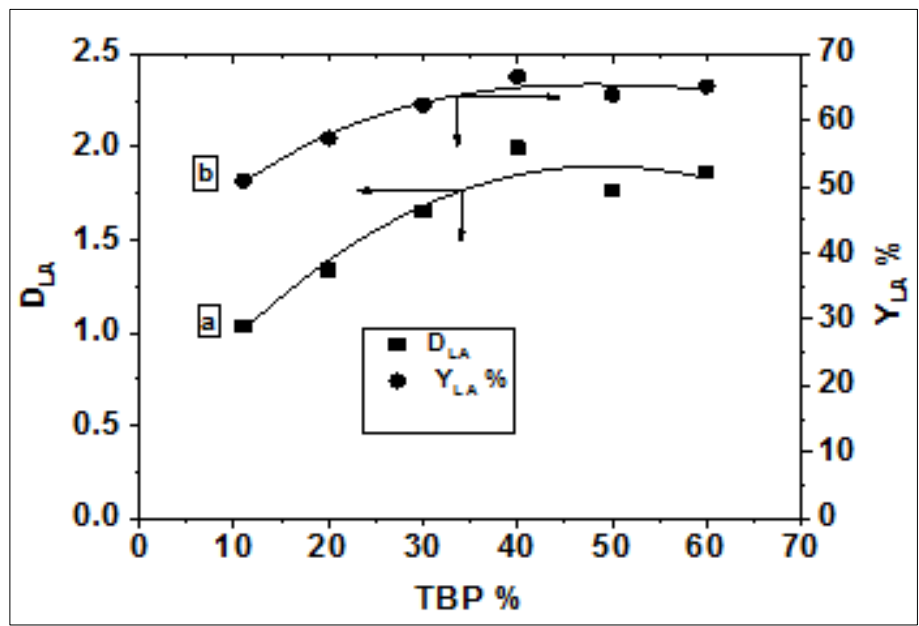

Figure 3a, b. Effect of TBP\% on $\mathrm{D}_{\mathrm{LA}}$ and $\mathrm{Y}_{\mathrm{LA}} \%$ at constant TOA concentration 


\subsubsection{Effect of $\mathrm{V}_{\text {org }} / \mathrm{V}_{\text {aq }}$ on LA extraction by 0.8M TOA + 11\% TBP}

An aqueous phase of $0.8 \mathrm{M} \mathrm{TOA}+11 \%(\mathrm{v} / \mathrm{v})$ TBP diluted in kerosene were stirred at $30^{\circ} \mathrm{C}$ for $1 \mathrm{~h}$ with an aqueous phase of whey of yoghurt and varying the volume of organic to aqueous phase ratio $\mathrm{V}_{\text {org }} / \mathrm{V}_{\mathrm{aq}}$ from 1 to 20. The data of extraction of LA were plotted in Figure $4 \mathrm{a}$ and $\mathrm{b}$ in the form of $\mathrm{D}_{\mathrm{LA}}$ and $\mathrm{Y}_{\mathrm{LA}} \%$ against $\mathrm{V}_{\text {org }} / \mathrm{V}_{\text {aq }}$ respectively. Figure $4 \mathrm{a}$ and $\mathrm{b}$ indicated that there are an increase of distribution ratio and yield of extraction of LA with increasing $\mathrm{V}_{\text {org }} / \mathrm{V}_{\text {aq }}$ and the maximum values of $\mathrm{D}_{\mathrm{LA}}$ $=1.8$ and $\mathrm{Y}_{\mathrm{LA}}=65 \%$ were observed for $\mathrm{V}_{\mathrm{org}} / \mathrm{V}_{\mathrm{aq}}=20$.

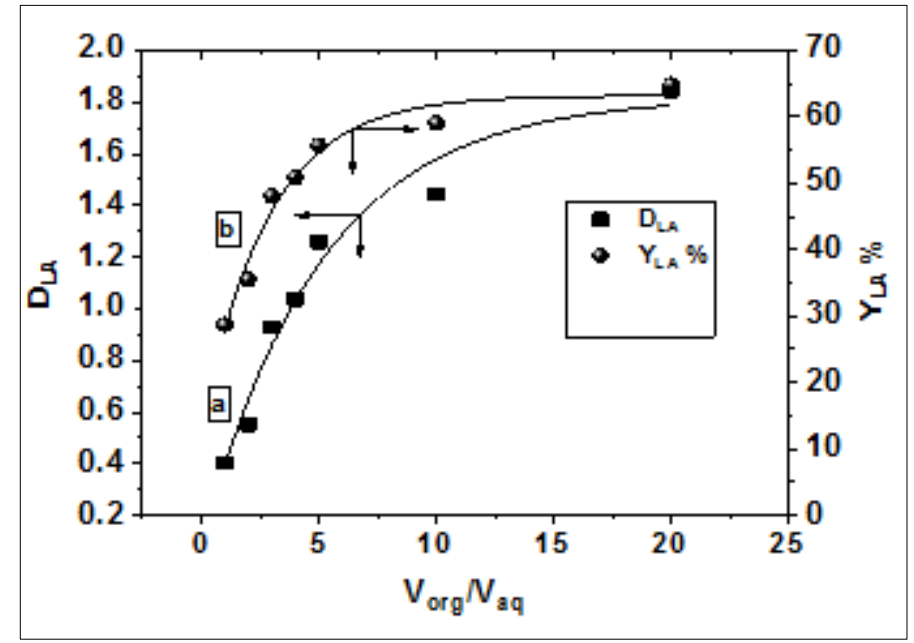

Figure 4a and b. Effect of $\mathrm{V}_{\mathrm{org}} / \mathrm{V}_{\mathrm{aq}}$ on $\mathrm{D}_{\mathrm{LA}}$ and $\mathrm{Y}_{\mathrm{LA}} \%$

\subsubsection{Effect of temperature on LA extraction}

To investigate whether the extraction reaction of LA from whey with $0.8 \mathrm{M}$ TOA $+11 \%$ TBP / kerosene is exothermic or endothermic, the temperature were varied from 30 to $55^{\circ} \mathrm{C}$ and at the same time, the volume of organic to aqueous phase ratio $=4 / 1$ was kept constant. The findings of extraction experiments were illustrated in Figure $5(a$ and $b)$ in the form of $\mathrm{Y}_{\mathrm{LA}} \%$ as a function of temperature and $\log D_{\text {LA }}$ against $1 / T$ respectively, it is shown that the temperature had a negative effect on $\log \mathrm{D}_{\mathrm{LA}}$ and $\mathrm{Y}_{\mathrm{LA}} \%$ which indicates that the extraction reaction of LA by TOA+TBP is exothermic. From the slope of straight line $\log \mathrm{D}_{\mathrm{LA}}=\mathrm{f}(1 / \mathrm{T})$ showed in Figure 5, the apparent enthalpy change $\left(\Delta \mathrm{H}^{\circ}\right)$ of the extraction reaction of LA was calculated and found to be $-11.695 \mathrm{~kJ} / \mathrm{mol}$. So, doing the extraction at low temperature is beneficial and gives a high distribution ratio and high extraction yield of LA, which consequently reduces the operation cost of extraction.

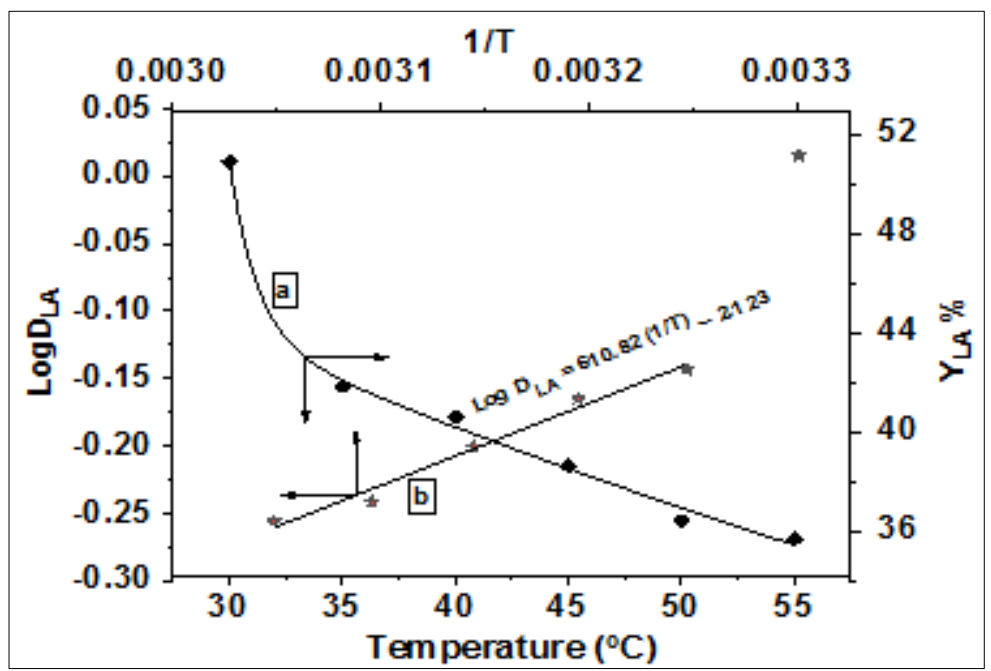

Figure 5a and b. Effect of temperature on $\mathrm{D}_{\mathrm{LA}}$ and $\mathrm{Y}_{\mathrm{LA}} \%$ 


\subsubsection{Effect of $\mathrm{NaCl}$ concentration on $\mathrm{LA}$ extraction}

Different amounts of $\mathrm{NaCl}(1.461,2.922,5.844,8.7665$ and $11.689 \mathrm{~g})$ were put into $100 \mathrm{~mL}$ volumetric flask then dissolved by whey of yoghurt, the final volume was adjusted to $100 \mathrm{~mL}$ by the same whey. $25 \mathrm{~mL}$ of the prepared aqueous solutions were put into contact with $25 \mathrm{~mL}$ of the organic phase $0.8 \mathrm{M} \mathrm{TOA}+11 \% \mathrm{TBP} /$ kerosene and magnetically stirred in water bath of $30^{\circ} \mathrm{C}$, for $1 \mathrm{~h}$, then the aqueous phase were separated by separatory funnel from the solvent after two hour of settlement, afterwards, LA was titrated in the whey before and after extraction by $0.01 \mathrm{~N} \mathrm{NaOH}$, the data of extraction in the form of $\mathrm{D}_{\mathrm{LA}}$ and $\mathrm{Y}_{\mathrm{LA}} \%$ against the added $\mathrm{NaCl}$ concentration to the whey, were presented in Figure 6.

It was observed from Figure 6 that $\mathrm{NaCl}$ played a positive effect on LA extraction since, the distribution ratio $D_{\mathrm{LA}}$ and the yield of extraction $\mathrm{Y}_{\mathrm{LA}}$ were increased from $\left(\mathrm{D}_{\mathrm{LA}}=0.493, \mathrm{Y}_{\mathrm{LA}}=33.04\right)$ to $\left(\mathrm{D}_{\mathrm{LA}}=1.92, \mathrm{Y}_{\mathrm{LA}}=65.75 \%\right)$ with increasing the added sodium chloride concentration from (0 to 2 $\mathrm{mol} / \mathrm{L}$ ) respectively, in the whey. So, $\mathrm{NaCl}$ played a role as salting out agent.

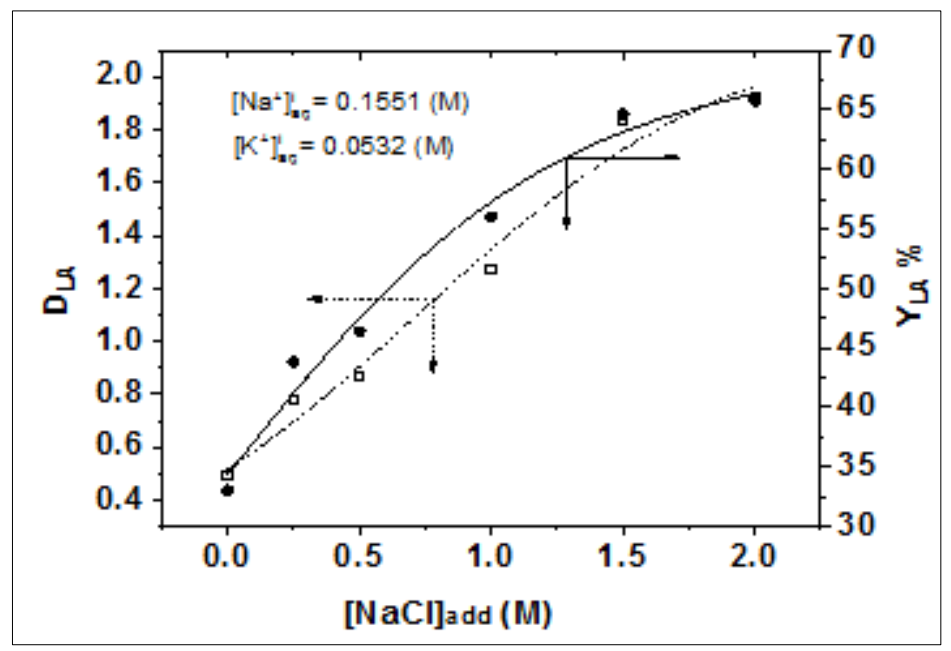

Figure 6. Effect $\mathrm{NaCl}$ concentration on LA extraction

\subsubsection{Effect of number of contact on LA extraction}

To elucidate the effect of the number of contacts $(\mathrm{N})$ on LA extraction, the organic phase $0.8 \mathrm{M}$ TOA $+11 \% \mathrm{TBP} /$ kerosene was put into contact with the whey of yoghurt for seven successive times for $1 \mathrm{~h}$, at organic to aqueous phase ratio of 1 , and maintaining the temperature to $30^{\circ} \mathrm{C}$, the findings of extraction were presented in Figure 7 in the form of $[\mathrm{LA}]_{\text {org }}$ as a function of the number of contact $(\mathrm{N})$.

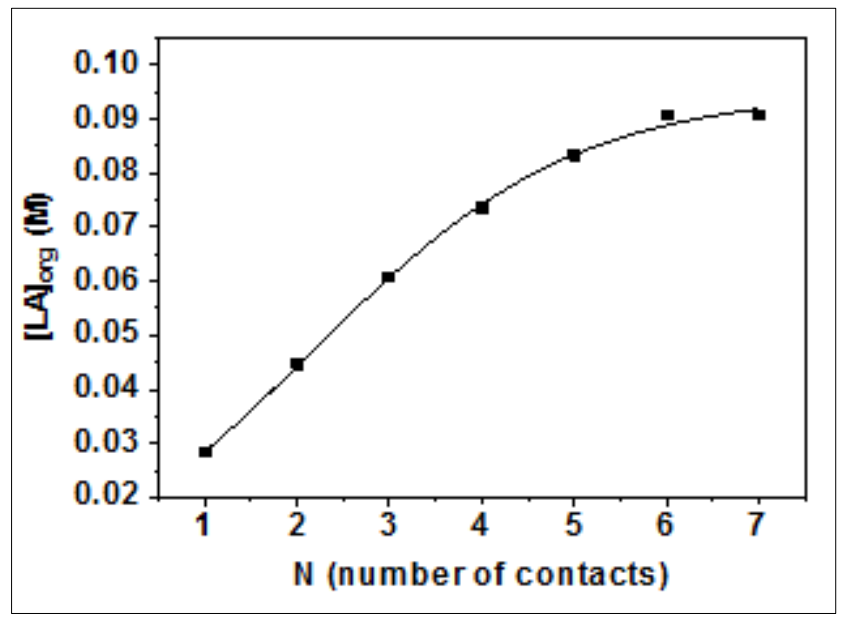

Figure 7. Effect of the number of contacts on LA extraction 
It is obvious from Figure 7 that the concentration of LA in the organic phase increases from 0.0283 to $0.091 \mathrm{~mol} / \mathrm{L}$, by increasing $\mathrm{N}$ from 1 to 6 . The maximum LA concentration in the organic phase was $0.091 \mathrm{~mol} / \mathrm{L}$ at $\mathrm{N}=6$, after that no fundamental changes were observed on the LA concentration in the organic phase.

\subsubsection{Stripping of LA from the loaded solvent 0.8M TOA + 11\% TBP/kerosene}

The organic phase $0.8 \mathrm{M}$ TOA $+11 \% \mathrm{TBP} /$ kerosene loaded with $0.0404 \mathrm{M}$ of lactic acid was stripped with double distilled water at two different temperatures 60 and $74{ }^{\circ} \mathrm{C}$, the aqueous to organic phase ratios were $(1,2,4,6,8,10$ and 20). The results of stripping experiments were illustrated in Figure 8 in the form of the yield of LA stripping ( $\mathrm{Y}^{\mathrm{La}}$ stripp \%) as a function of $\mathrm{V}_{\mathrm{aq}} / \mathrm{V}_{\text {org }}$ ratio. No big difference on $\mathrm{Y}^{\mathrm{La}}$ stripp $\%$ was observed when the temperature was raised from 60 to $74^{\circ} \mathrm{C}$ and only just $1 \%$ more of $\mathrm{Y}^{\mathrm{La}}$ stripp $\%$ at $74^{\circ} \mathrm{C}$ in comparison with $\mathrm{Y}^{\mathrm{La}}$ stripp $\%$ at $60^{\circ} \mathrm{C}$. While the aqueous to organic phase ratio played a decisive role on LA stripping process, since, the yield of stripping was increased from $27.9 \%$ to $85.09 \%$ when the $\mathrm{V}_{\text {aq }} / \mathrm{V}_{\text {org }}$ was raised from 1 to 20 respectively. The stripped solution was so clear and no third phase was observed in the range of $\mathrm{V}_{\mathrm{aq}} / \mathrm{V}_{\text {org }}=4-20$, but at $\mathrm{V}_{\mathrm{aq}} / \mathrm{V}_{\text {org }}=1$ or 2 , the time of separation between organic and aqueous phases during the settlement was so long, and an emulsion was occurred. It is noteworthy to say that for complete stripping of LA from the organic phase, the number of stripping stages should be 2 when $\mathrm{V}_{\mathrm{aq}} / \mathrm{V}_{\text {org }}=20$.

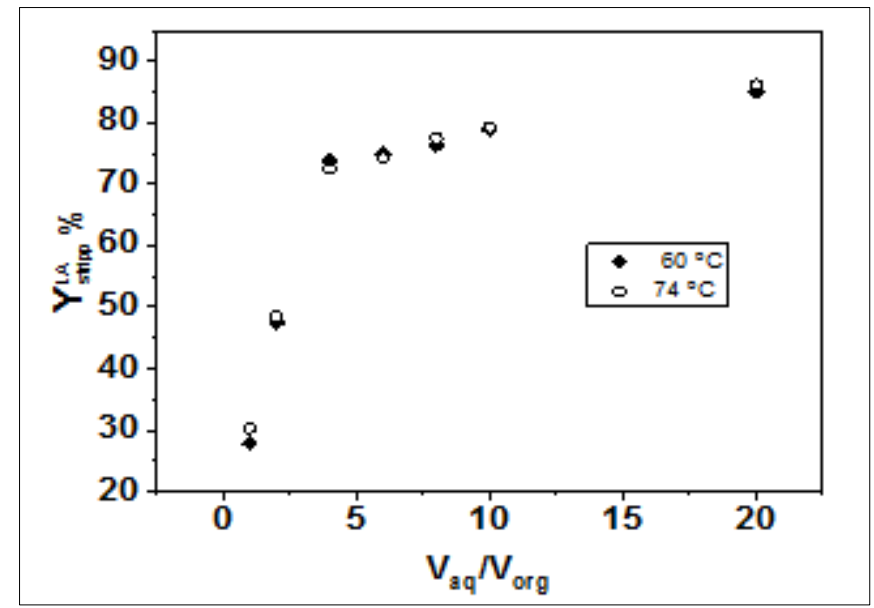

Figure 8. Stripping of LA from the loaded organic phase $0.8 \mathrm{M}$ TOA $+11 \% \mathrm{TBP} /$ kerosene

\subsubsection{Flow sheet for LA extraction from whey of yoghurt}

From the results obtained from this work, the following flow sheet (Figure 9) can be suggested to recover LA from the whey of yoghurt.

After filtration of whey of yoghurt, the obtained feed solution will be submitted to a solvent extraction process, using an organic extractant consisted of $0.8 \mathrm{M}$ TOA and $11 \%$ TBP diluted in kerosene, then the loaded organic phase will be stripped with double distilled water at $60^{\circ} \mathrm{C}$ in two stages for complete stripping of LA. Then the pure dilute LA solution coming from stripping unit will be concentrated by evaporation and finally submitted to crystallization process, which lead to pure lactic acid. 


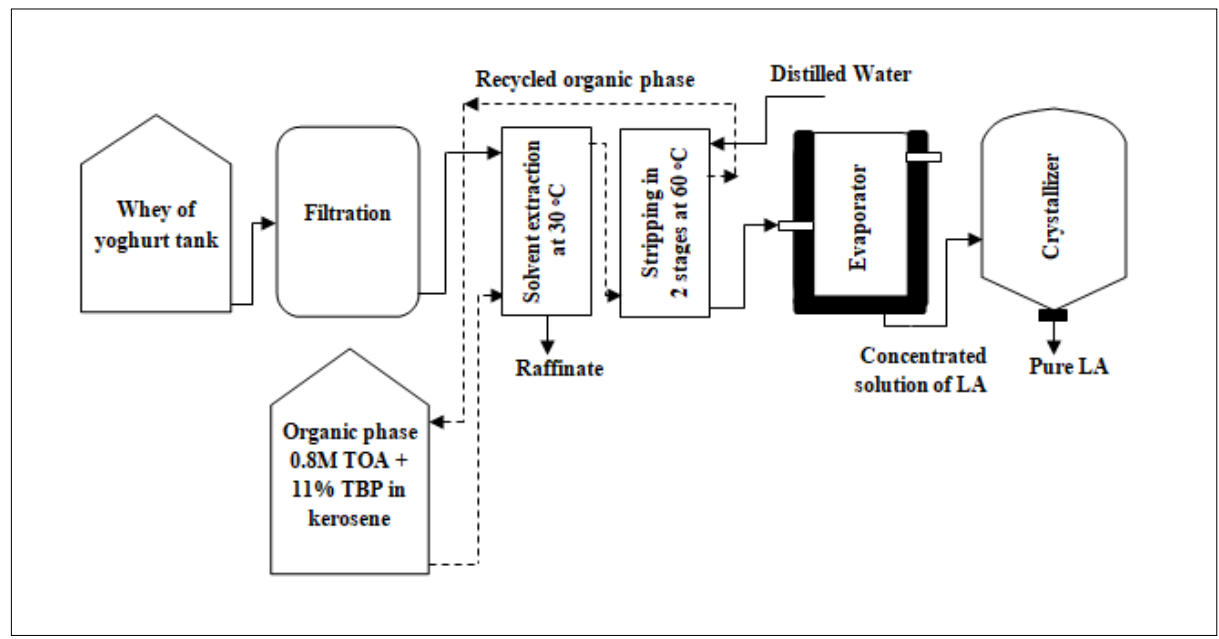

Figure 9. Simple flow sheet of LA recovery from whey of yoghurt

\section{Conclusions}

Whey of yoghurt should be taken into consideration as a valuable source of LA.

Liquid-Liquid extraction technique is effective and easy way to recover LA from whey of yoghurt.

Tri-n- octyl amine/kerosene containing tri-n-butyl phosphate as modifier and synergistic can be successfully applied to extract and recover LA from the whey.

Temperature of extraction should be $30^{\circ} \mathrm{C}$ since the extraction of LA by amine was found to be exothermic, while the des-extraction process should be done at $60^{\circ} \mathrm{C}$.

$\mathrm{V}_{\text {org }} / \mathrm{V}_{\text {aq }}$ phase ratio for easy and practical operation should be equal to $4 / 1$.

The kinetic of extraction of LA from whey is slow, and should be carried out for at least $1 \mathrm{~h}$ to reach the equilibrium.

One stage of extraction is not sufficient to recover the whole LA from the whey. So, the yield of LA extraction can be increased by increasing the number of extraction stages.

LA can be stripped from the loaded organic phase $0.8 \mathrm{M}$ TOA $+11 \% \mathrm{TBP} / \mathrm{kerosene}$ by double distilled water at $60^{\circ} \mathrm{C}$ in 2 stripping stages.

Acknowledgments: The authors would like to express their gratitude to Prof I. OTHMAM (General Director of Atomic Energy Commission of Syria) for financial support and encouragement and to Prof A. ALLAF (Head of Chemistry Department) for fruitful discussions as well as to Mrs R. BOUZO for determination of mineral concentration in whey by AAS and also to N. WAHBA for helping, in doing the experiments.

\section{References}

1.KOMESU, B., MACIEL, M. R. W., ROCHADEOLIVEIRA, J. A., Purification of Lactic Acid Produced by Fermentation, Sep. Purif. Rev., 46 (3), 2017, 241-254.

https://doi.org/10.1080/15422119.2016.1260034

2.DWORKIN, M., FALKOW, S., ROSENBERG, E., SCHLEIFER, K. H., STACKEBRANDT E., The Prokaryotes, A Handbook on the Biology of Bacteria: Symbiotic Associations, Biotechnology, Applied Microbiology, 3ed edition, Volume 1, 2006

3.HÁBOVÂ, V., MELZOCH, K., RYCHTERA, M., Modern method of lactic acid recovery from fermentation broth, Czech J. Food Sci., 22(3), 2004, 87-94. https://doi.org/ 10.1722/3411-CJFS

4.KYUCHOUKOV, G., MARINOVA, M., MOLINIER, J., ALBERT, J., MALMARY, G., Extraction of lactic acid by means of mixed extractant, Ind. Eng. Chem. Res.,40 (23), 2001, 5635-5639.

https://doi.org/10.1021/ie010137d 
5.YAMAMOTO, T., KOJIMA, K., MORI, H., KAWASAKI, H., SAYAMA, M., Extraction of lactic acid using long chain amines dissolved in non-polar diluents, J. Chem. Eng. Jpn., 44 (12), 2011, 949956. https://doi.org/10.1252/jcej.11we110

6.MATSUMOTO, M., SHIBAZAKI, M., YUASA, R., KONDO, K., Salting -out extraction of 3hydroxypropionic acid with reactive extraction and aqueous two-phase systems, Solvent Extr. Res. Dev., Jpn., 24 (2), 2017, 141-147. https://doi.org/10.15261/serdj.24.141

7.CHAWONG, K., RAYABSRI, C., RATTANAPHANEE, P., Extraction of lactic acid in mixed solvent electrolyte system containing water, 1-Butanol and Ammonium sulfate, Int. J. Chem. React. Eng., 13 (2), 2015, 183-188. https://doi.org/10.1515/ijcre

8. MUNGMA, N., KIENBERGER, M., KRACIK T., SIEBENHOFER, M., Reactive extraction of lactic acid from an alkaline aqueous solution with an ammonium-based ionic liquids, Int. J. Res. Eng. Sci.,6 (8), 2018, 30-38

9.KLASSON, K. T., RIDENOUR, W. B., DAVISON, B. H., McFARLANE, J., Direct capture of organic acids from fermentation media using ionic liquids. ORNL/TM 2004/192.

https://doi.org/10.2172/861707

10.Li, Q., JIANG, X., ZOU, H., CAO, Z., ZHANG, H., XIAN, M., Extraction of short-chain organic acids using imidazolium-based ionic liquids from aqueous media, J. Chem. Pharm. Res.,6 (5), 2014, 374-381.

11. MAlmaRY, G., ALBERT, J., PUTRANTO, A., HANINE, H., MOLINIER, J., Recovery of aconitic and lactic acids from simulated aqueous effluents of the sugar-cane industry through liquidliquid extraction, J. Chem. Technol. Biotechnol.,75 (12), 2000, 1169-1173.

https://doi.org/10.1002/1097-4660(200012)75:12<1169::AID-JCTB334>3.0.CO:2-F

12.HENRIUES, M. H. F., Recovery and application of whey proteins in conventional and nonconventional food system, PhD theses, University of Coimbra, Portugal, 2012.

Manuscript received: 14.02 .2021 